\title{
Method to Improve the Accuracy of Slope Monitoring Data Based on a Measuring Robot
}

\author{
http://dx.doi.org/10.3991/ijoe.v11i1.4269 \\ Yandong $\mathrm{GAO}^{1}$, Maolin $\mathrm{XU}^{1 *}$, YachunMao ${ }^{2}$ \\ ${ }^{1}$ College of Mining Engineering Institute, University of Science and Technology Liaoning, Anshan, China; \\ ${ }^{2}$ Northeastern University, Shenyang, China;
}

\begin{abstract}
To improve the accuracy of slope monitoring data based on a measuring robot, an effective and viable correction method is proposed. A 3D monitoring system based on a measuring robot and Geomos is utilized to collect data. The monitoring data of 44 cycles of Dagushan and Yanqianshan open-pit iron mines in Anshan City are employed as the data source. Large amounts of data are calculated and compared, and a quantitative analysis of various factors that influence the accuracy of measuring robot is performed. Data calculation shows that the proposed mathematical meteorological correction model and directional deviation correction method can effectively improve the accuracy of measuring robot. The corrected data can accurately represent the displacement of monitoring points, which provides important real-time warning of open-pit slope landslides. Methods to improve the accuracy of measuring robot are studied to increase data reliability. The nature of the data and the factors that affect the quality of data are analyzed.
\end{abstract}

Index Terms-open-pit mine, measuring robot, slope monitoring, monitoring data accuracy

\section{INTRODUCTION}

In the high-precision deformation monitoring process, the accuracy of measuring robot is always overshadowed by the precision of measuring robot [1]. Precision involves the evaluation of measurement data reliability and a description of the average values of numerous repeated measurements in terms of random errors. The overall accuracy and degree of deviation of numerous measurement results is affected mainly by systematic errors. Compared with traditional monitoring methods, the velocity of the measuring robot is more faster, the more save manpower and material resources, the the higher precision and other advantages, but the accuracy of the measuring robot is a key factor affecting the quality of monitoring data. High-precision monitoring data produce high-accuracy monitoring results. Monitoring results with high accuracy reflect the status of each monitored point and slope stability [2-6]. Hence, appropriate judgments should be made.

A monitoring system based on a $3 \mathrm{D}$ robot and Geomos has been utilized in studies on open-pit slope monitoring [7-11]. These studies found that the main factors that affect the accuracy of measuring robot include atmospheric refraction and station orientation correction in various monitoring points. Changes in atmospheric refraction physical quantities at different times in a day would result in changes in distance data if real-time monitoring distance correction is implemented. Hence, the accuracy of measuring robot would be affected. The impact of this factor in different seasons makes each cycle of monitoring data more prominent. The large temperature difference between summer and winter in Northeast China increases with increased distance. The impact value reaches up to 1 $\mathrm{km}$ from the centimeter level, which is not a negligible magnitude in rock slope monitoring. The impact of station orientation correction is another factor that should not be neglected in measuring robot accuracy. Compared with the influence of atmospheric refraction errors and instrument systems, the directional bias of instruments reflects the magnitude and direction of uncertainties, and their degree of influence on measuring robot accuracy is much larger than that of the former. Thus, the displacement accuracy of different monitoring cycles is affected. In this study, experimental data on the above mentioned two factors are analyzed systematically. An effective means to improve the accuracy of measuring robot is proposed [1213]. The study has practical significance for the processing of open-pit slope monitoring data.

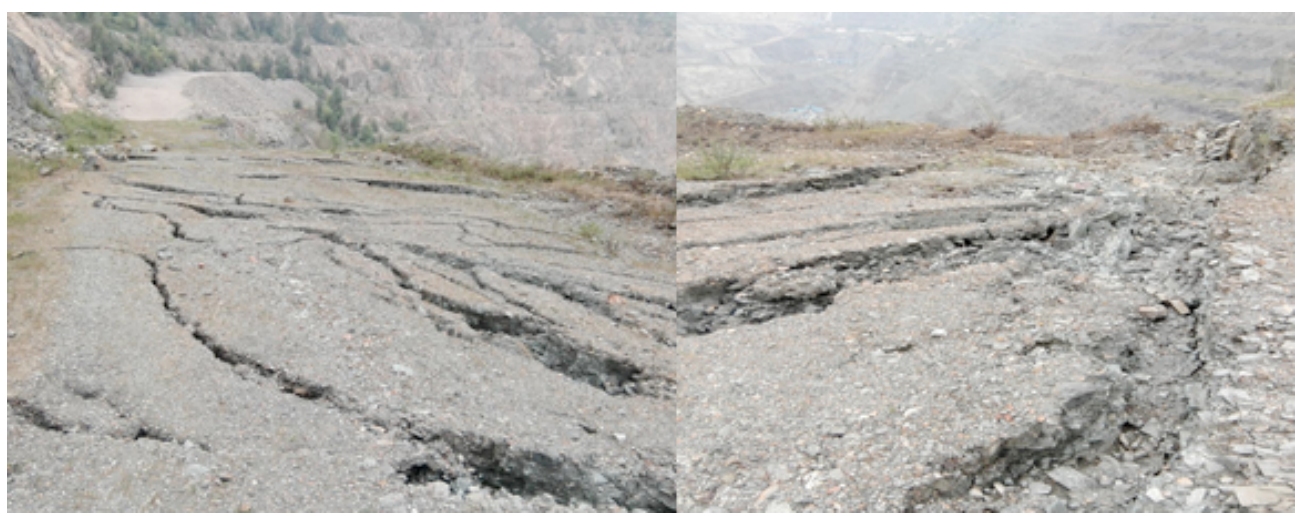

Figure 1. Landslide site 


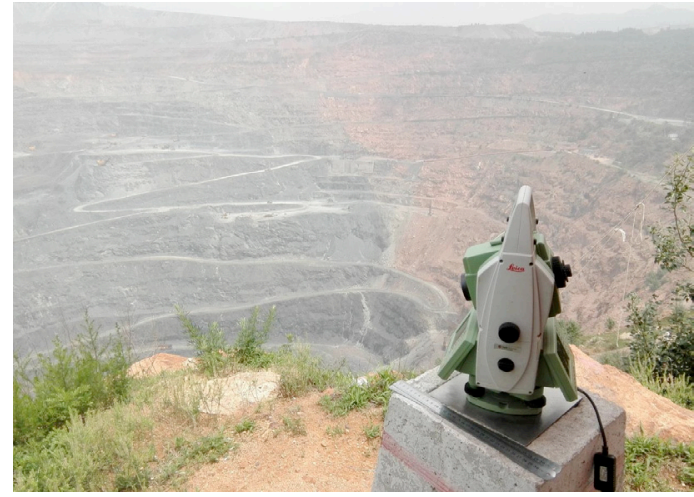

Figure 2. Monitoring site at Dagushan open-pit iron mine in Anshan

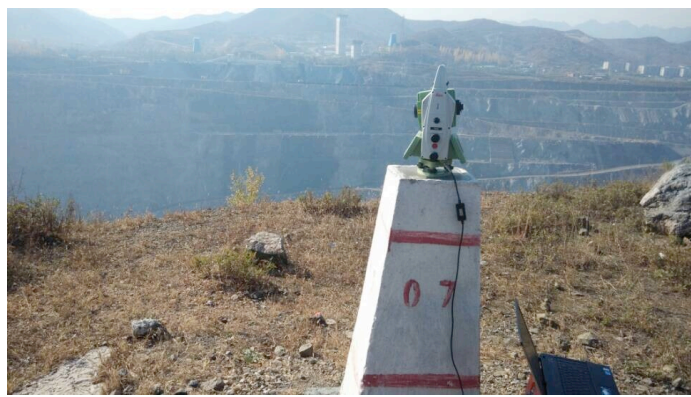

Figure 3. Monitoring site at Yanqianshan open-pit iron mine in Anshan

\section{IMPACT OF ATMOSPHERIC CONDITIONS ON THE ACCURACY OF MONITORING DATA}

Given that the measuring robot carrier (TM30) is a laser, the temperature, air pressure, and relative humidity of the carrier have different effects in different conditions. Hence, different weather conditions will produce different measurement results. Monitoring open-pit mine slopes generally require much working time and can even last for years. The daily temperature in northeast China reaches $15^{\circ} \mathrm{C}$ to $25^{\circ} \mathrm{C}$ in winter and up to $60^{\circ} \mathrm{C}$ in summer, especially in open-pit iron mines, where the distribution at the bottom of the pit involves complicated atmospheric conditions. In actual monitoring processes, the range of the optical path curves involves distance across the pit. Therefore, accurately measuring meteorological parameters and implementing weather correction are necessary work to improve the accuracy of monitoring data base on measuring robot; otherwise, the accuracy of monitoring results cannot be guaranteed [14-15].

\section{A. TM30 meteorological correction mathematical model}

In the entire station, the results are affected not only by exposure to atmospheric refraction but also by the carrier of measuring robot . Under actual weather conditions, the design formula for modulated refractive index $\mathrm{n}$ is [16]

$$
n=1+\frac{n_{g}-1}{1+a \times t} \times \frac{P}{760}-\frac{5.5 \times 10^{-8} \times e}{1+\alpha \times t}
$$

where $=1 / 273.16$ is the air expansion coefficient, is the actual dry air temperature (in ${ }^{\circ} \mathrm{C}$ ), is the actual atmospheric pressure (in $\mathrm{mmHg}$ ), and is the actual water vapor pressure (in $\mathrm{mmHg}$ ). is modulated under standard meteorological conditions ( $=0 \square,=760 \mathrm{mmHg},=0 \mathrm{mmHg}$ ) to obtain the refractive index of light. The formula is

$$
n_{g}=n_{\lambda}-\lambda \frac{d n_{\lambda}}{d \lambda}
$$

where is monochromatic wavelength(in) and is nonmonochromatic light refractive index modulation under standard weather conditions calculated as (Barrell-Sears)

$$
\left(n_{\lambda}-1\right) \times 10^{7}=2876.04+\frac{16.288}{\lambda^{2}}+\frac{0.136}{\lambda^{4}}
$$

From the above equation, we obtain

$$
\frac{d n_{\lambda}}{d \lambda}=\left(-\frac{2 \times 16.288}{\lambda^{3}}-\frac{4 \times 0.136}{\lambda^{5}}\right) \times 10^{-7}
$$

Eqs. (3) and (4) are substituted into Eq. (2) as follows:

$$
n_{g}=1+\left(2876.04+\frac{3 \times 16.288}{\lambda^{2}}+\frac{5 \times 0.136}{\lambda^{4}}\right) \times 10^{-7}
$$

The distance wavelength of the measuring robot is = 0.65. Hence, with Eq. (5), we obtain. By employing the values in Eq. (1), we have

$$
n-1=\left(\frac{0.394145 \times P}{1+\alpha \times t}-\frac{5.5 \times 10^{-2} \times e}{1+\alpha \times t}\right) \times 10^{-6}
$$

In Leica Station, air pressure is generally expressed in the pressure unit millipascal $(\mathrm{mb})$. Hence, according to $1 \mathrm{mmHg}=1.33322 \mathrm{mb} \approx 4 / 3 \mathrm{mb}$ and $1 \mathrm{mb}=100 \mathrm{~Pa}$, Eq. (6) can be rewritten as

$$
n-1=\left(\frac{0.295609 \times P}{1+\alpha \times t}-\frac{4.126 \times 10^{-2} \times e}{1+\alpha \times t}\right) \times 10^{-6}
$$

The measuring robot is generally defined in standard weather conditions, namely, temperature $\mathrm{t}=12^{\circ} \mathrm{C}$, pressure $\mathrm{P}=1013.25 \mathrm{mb}$, and relative humidity $\mathrm{h}=60 \%(\mathrm{t}=$ $8.3^{\circ} \mathrm{C}$, e is vapor pressure), according to the formula

$$
e=e^{\prime}-0.000662 \times\left(t-t^{\prime}\right)\left(1+0.001146 t^{\prime}\right) \times P
$$

$$
e^{\prime}=6.107 \times 10^{a}, a=\frac{7.5 \times t^{\prime}}{237.3+t} \text {. }
$$

The measuring robot can calculate the benchmark index of refraction for the entire station.

We let

$$
\begin{gathered}
N_{0}=\left(n_{0}-1\right) \times 10^{6} \\
N=(n-1) \times 10^{6}
\end{gathered}
$$

The atmospheric refractive index range of the impact on the meteorological correction formula is

$$
\Delta D=\left(n_{0}-n\right) \times D=\left(N_{0}-N\right) \times 10^{-6} \times D
$$

namely,

$\Delta D=\left[281.8-\left(\frac{0.295609 \times P}{1+\alpha \times t}-\frac{4.126 \times 10^{-4} \times e}{1+\alpha \times t}\right)\right] \times 10^{-6} \times D$

In the formula, $\mathrm{D}$ is the distance to be measured. $\Delta D$ calculated by the saturation vapor pressure $(E)$ and relative humidity $(h)$, that is $E=10^{x}, x=\frac{7.5 \times t^{\prime}}{237.3+t}+0.785$ and $h=e / E$. Eq. (11) can be rewritten as

$$
\Delta D=\left[281.8-\left(\frac{0.295609 \times P}{1+\alpha+t}-\frac{4.126 \times 10^{-2} \times h}{1+\alpha+t} \times 10^{x}\right)\right] \times 10^{-6} \times D
$$

In the formula, $\mathrm{D}$ is the distance to be measured, $\Delta D$ is the meteorological scale factor correction, $\mathrm{P}$ is atmospheric pressure $(\mathrm{mb}), \mathrm{t}$ is dry temperature $\left({ }^{\circ} \mathrm{C}\right), \mathrm{h}$ is relative humidity (\%), and $\alpha$ is the atmospheric expansion coefficient, where $\alpha=1 / 273.16$. 


\section{B. Comparative analysis of different meteorological cor-} rections in different seasons

To obtain a more accurate distance in measuring the meteorological parameters of the optical path to correct the curve, two thermometers, hygrometers, and barometers were utilized in the station points and monitoring sites to measure the temperature, relative humidity, and air pressure. Their mean value was regarded as the range of the optical path curve of the meteorological parameters. With 2013 Yanqianshan open-air monitoring data (from the viewpoint of iron ore and meteorological monitoring data), Eq. (12) was utilized to calculate the correct value of the edge throughout the year. Table 1 shows the values and meteorological monitoring corrections of the edge [17-18].

As shown in Table 1, the edge has a relatively small correction value in spring and autumn, whereas the correction value is large in winter and summer. The relative change in volume reached $48.6 \mathrm{~mm}$. Therefore, to improve the accuracy of measuring robot, accurate distance measurement in measuring the physical parameters of the optical path of the atmospheric refraction curve is required along with monitoring of the side length of meteorological correction.

C. Analysis of significant physical parameters of each atmospheric refraction effect on distance
Air pressure, temperature, and relative humidity are the three main factors of atmospheric refraction that affect the physical distance of the optical path length of the curve. However, their effect on distance is not the same. A systematic analysis was conducted, and the amount of change and corresponding line are acquired from the influence of various factors (Tables II to IV and Figures 4 to 6).

As shown in Table II, when air pressure and temperature are in standard conditions, meteorological corrections decrease as relative humidity increases. The maximum correction value is $5 \mathrm{~mm}$, and the minimum correction value is $4.8 \mathrm{~mm}$. The change has minimal impact on the correction side.

Table III shows that when air pressure and relative humidity are in standard conditions, meteorological corrections increase with the increase in temperature. The value of meteorological corrections reached the centimeter level. The largest correction value is $12.9 \mathrm{~mm}$, and the minimum correction value is $-6.9 \mathrm{~mm}$. The temperature changes in side length correction have a large impact.

Table IV shows that when temperature and relative humidity are in standard conditions, meteorological correction increases with the decrease in air pressure. The maximum value of correction is $10.3 \mathrm{~mm}$, and the minimum correction value is $-1 \mathrm{~mm}$. The change in air pressure affects the correction for temperature and relative humidity.

TABLE I. INFLUENCE OF DIFFERENT SEASONAL WEATHER CHANGES ON LOCATION

\begin{tabular}{cccccc}
\hline Season & $\begin{array}{c}\text { Measured distance } \\
\text { / }\end{array}$ & $\begin{array}{c}\text { Air Pressure } \\
\text { / } \mathbf{m b}\end{array}$ & $\begin{array}{c}\text { Temperature } \\
/{ }^{\circ} \mathbf{C}\end{array}$ & $\begin{array}{c}\text { Relative humidity } \\
/ \%\end{array}$ & $\begin{array}{c}\text { Meteorological corrections } \\
/ \mathbf{m}\end{array}$ \\
\hline Spring & 1000.42542 & 1000.1 & 7.7 & 25.6 & -0.0056 \\
Summer & 1000.42542 & 989.9 & 30.4 & 52.5 & 0.0193 \\
Autumn & 1000.42542 & 999.9 & 18.8 & 44.3 & 0.0056 \\
Winter & 1000.42542 & 1003.3 & -12.8 & 36.2 & -0.0293 \\
\hline
\end{tabular}

TABLE II. AIR PRESSURE AND TEMPERATURE IN STANDARD CONDITIONS AND RELATIVE HUMIDITY OF $10 \%$ TO INCREASE THE EFFECTS OF METEOROLOGICAL CORRECTION

\begin{tabular}{cccccc}
\hline No & $\begin{array}{c}\text { Measured distance } \\
\text { /m }\end{array}$ & $\begin{array}{c}\text { Air Pressure } \\
\text { / } \mathbf{m b}\end{array}$ & $\begin{array}{c}\text { Temperature } \\
/{ }^{\circ} \mathbf{C}\end{array}$ & $\begin{array}{c}\text { Relative humidity } \\
/ \%\end{array}$ & $\begin{array}{c}\text { Meteorological corrections } \\
\text { / }\end{array}$ \\
\hline 1 & 1000.42542 & 1013.25 & 12 & 20 & -0.0050 \\
2 & 1000.42542 & 1013.25 & 12 & 30 & -0.0050 \\
3 & 1000.42542 & 1013.25 & 12 & 40 & -0.0049 \\
4 & 1000.42542 & 1013.25 & 12 & 50 & -0.0048 \\
5 & 1000.42542 & 1013.25 & 12 & 60 & -0.0048 \\
\hline
\end{tabular}

TABLE III. AIR PRESSURE AND RELATIVE HUMIDITY IN STANDARD CONDITIONS AND TEMPERATURE OF $5{ }^{\circ} \mathrm{C}$ TO INCREASE EFFECT OF METEOROLOGICAL CORRECTION

\begin{tabular}{cccccc}
\hline No & $\begin{array}{c}\text { Measured distance } \\
\text { / }\end{array}$ & $\begin{array}{c}\text { Air Pressure } \\
\text { / } \mathbf{m b}\end{array}$ & $\begin{array}{c}\text { Temperature } \\
/{ }^{\circ} \mathbf{C}\end{array}$ & $\begin{array}{c}\text { Relative humidity } \\
\text { /\% }\end{array}$ & $\begin{array}{c}\text { Meteorological corrections } \\
\mathbf{~} \mathbf{m}\end{array}$ \\
\hline 1 & 1000.42542 & 1013.25 & 10 & 60 & -0.0069 \\
2 & 1000.42542 & 1013.25 & 15 & 60 & -0.0017 \\
3 & 1000.42542 & 1013.25 & 20 & 60 & 0.0032 \\
4 & 1000.42542 & 1013.25 & 25 & 60 & 0.0081 \\
5 & 1000.42542 & 1013.25 & 30 & 60 & 0.0129 \\
\hline
\end{tabular}

TABLE IV. TEMPERATURE AND RELATIVE HUMIDITY IN STANDARD CONDITIONS AND AIR PRESSURE OF 10 MB TO INCREASE EFFECT OF METEOROLOGICAL CORRECTION

\begin{tabular}{cccccc}
\hline No & $\begin{array}{c}\text { Measured distance } \\
\text { / }\end{array}$ & $\begin{array}{c}\text { Air Pressure } \\
\text { / } \mathbf{m b}\end{array}$ & $\begin{array}{c}\text { Temperature } \\
/{ }^{\circ} \mathbf{C}\end{array}$ & $\begin{array}{c}\text { Relative humidity } \\
/ \%\end{array}$ & $\begin{array}{c}\text { Meteorological corrections } \\
/ \mathbf{m}\end{array}$ \\
\hline 1 & 1000.42542 & 1000 & 12 & 60 & -0.0010 \\
2 & 1000.42542 & 990 & 12 & 60 & 0.0018 \\
3 & 1000.42542 & 980 & 12 & 60 & 0.0046 \\
4 & 1000.42542 & 970 & 12 & 60 & 0.0075 \\
5 & 1000.42542 & 960 & 12 & 60 & 0.0103 \\
\hline
\end{tabular}


As shown in Figures 4 to 6, temperature has the most significant influence on meteorological correction followed by air pressure. Relative humidity has the weakest influence. According to meteorological data obtained from the Anshan slope monitoring site for Dagushan, the annual amount of change in air pressure is between $992.1 \mathrm{mb}$ and $1012.4 \mathrm{mb}$. The annual temperature variation is between $-19.4^{\circ} \mathrm{C}$ and $36.3^{\circ} \mathrm{C}$. The annual variation in relative humidity is between $27.6 \%$ and $68.4 \%$. The large relative change in temperature had the most significant effect on distance. Thus, in the same period, the monitoring process should increase the frequency of temperature data collection to improve the accuracy of the mean temperature and achieve enhanced data accuracy.

\section{DiRECTIONAL BiAs EFFECT ON THE ACCURACY OF MONITORING DATA}

The computation for the center cross hair and resulting image center deviation would produce several errors because the ATR function in the internal CCD array of the measuring robot (TM30) was adjusted. The recognition resolution of the measurement robot decreased with the increase in distance. Hence, the instrument will exhibit bias when sighting a target. External conditions and human factors also have an impact on directional bias. According to the calculation results of the actual monitoring data, the deviation between $2 "$ to $6 "$ and its effect on the displacement deviation monitoring points increase with the increase in distance up to a few centimeters. In rock slope monitoring, this magnitude cannot be ignored; hence, the directional bias in monitoring the impact of data accuracy is not a negligible factor [19-22].

\section{A. Measuring robot (TM30) station directional devia-} tion analysis

In Figure 7, K1 denotes the station, $\mathrm{K} 2$ is after the point of view, is the viewpoint and monitoring by a known antibps calculated azimuth, and is measured by the actual azimuth aiming viewpoint. The difference between the two azimuths lies in their directional azimuth deviation. A is a point for monitoring because $\mathrm{A}$ and $\mathrm{K} 2$ comprise an observation point group; therefore, the same directional bias influences them. However, the size and symbols of directional bias vary in multiple monitoring cycles. Directional bias would thus have different effects on different cycles of monitoring point displacement accuracy. Therefore, directional orientation correction is an effective method to improve the accuracy of monitoring data.

B.Measuring robot (TM30) station directional bias correction method

Azimuth was $\alpha_{K 1-K 2}$ calculated according to the antiknown viewpoint and monitoring basis points. In the monitoring data measured after calculating the measured azimuth aiming for $\alpha_{K_{1-K^{2}}}^{\prime}$ viewpoint (for a point group ofmultiple rounds of azimuth mean), $\Delta \alpha$ is the point group of directional azimuth deviation. Thus, according to the references [23] in the point group, the corrected azimuth of monitoring point $\mathrm{A}$ is as follows:

$$
\begin{gathered}
\alpha_{A}=\alpha_{A}^{\prime}+\Delta \alpha \\
\Delta \alpha=\alpha_{k 1-k 2}-\alpha_{k 1-k 2}^{\prime},
\end{gathered}
$$

where $\alpha_{A}^{\prime}$ is the azimuth angle measured from $K_{1}$ to A. The coordinates of the point group after monitoring point A correction are

$$
\begin{gathered}
x_{A}=x_{k 1}+s \times \cos \alpha_{A} \\
y_{A}=y_{k 1}+s \times \sin \alpha_{A}
\end{gathered}
$$

Almost two years of data on Dagushan open-pit slope deformation monitoring projects in Anshan were calculated by the measuring robot (TM30). Stations 1 and 2 in Table $\mathrm{V}$ are the results of two different station orientation angle deviations.

Table $\mathrm{V}$ shows that in Station 1, the maximum directional deviation is $-5.59 "$, and the smallest directional deviation is 3.75". In Station 2, the maximum directional

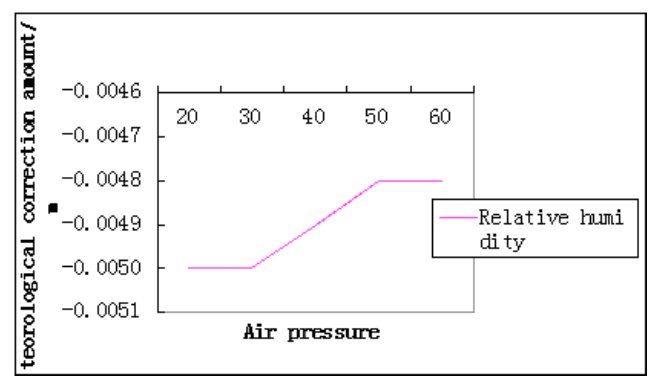

Figure 4. Relative humidity in the range effects chart

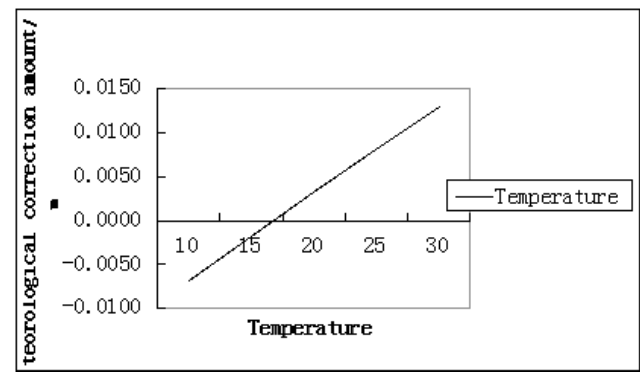

Figure 5. Temperature in the range effects chart

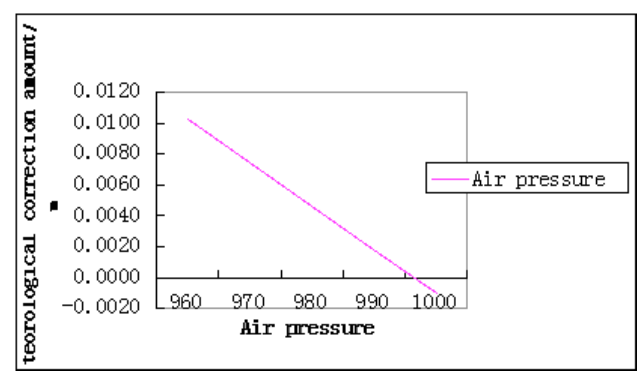

Figure 6. Air pressure in the range effects chart

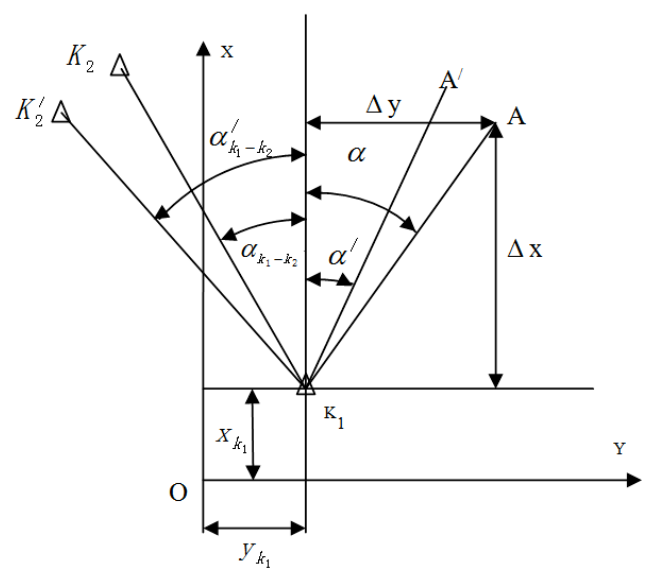

Figure 7. Directional angle deviation 
deviation is $-5.06 "$, and the smallest directional deviation is $-3.01 "$. The uncertainty in the size and sign of the orientation angle of deviation shows that if the orientation of the adjacent symbol period deviation angle has an opposite sign, a large impact would be exerted on the accuracy of the amount of displacement in the two cycles. The direction correction values for five monitoring sites in Station 1 are compared in Table VI to determine the impact point coordinates.

Table VI shows that the maximum and minimum values of correction in $\mathrm{x}$ direction are (61 monitoring points, $25 \mathrm{~mm}$ ) and (10 monitoring points, $-4 \mathrm{~mm}$ ), respectively. The maximum and minimum values of correction in $y$ direction are (2 monitoring points, $-25 \mathrm{~mm}$ ) and (61 monitoring points, $-16 \mathrm{~mm})$, respectively. Thus, directional bias has a large impact on monitoring data accuracy. Orientation bias correction is an effective means to improve the accuracy monitoring results.

\section{Verification Method To Improve The ACCURACY OF MONITORING DATA}

According to the monitoring data on Dagushan outdoor iron mine, the No. 3 monitoring points have 10 cycles.
Table VII shows a comparison of the amount of displacement change before and after correction for the NO. 3 monitoring points in $\mathrm{x}$ and $\mathrm{y}$ directions. The $\mathrm{x}$ and $\mathrm{y}$ coordinates after curve correction curve are shown in Figure 8.

Given that the NO. 3 monitoring points are located at the southwest end of mine, $x$ should be gradually increased according to objective facts. However, seven of the cycles in Table 7 show a correct amount of movement prior to $-3.8 \mathrm{~mm}$. This result is clearly inconsistent with objective facts. The proposed correction method was thus applied to make the data changes consistent with objective facts. As shown in Figure 8, the NO. 3 monitoring points in the $\mathrm{x}$ and $\mathrm{y}$ coordinate directions before fluctuation correction cannot express the consistency of slope movement. After applying the proposed method for data correction, data stability became significantly higher than before correction. Slope movement consistency was suitably expressed, indicating that the proposed correction method can effectively improve the accuracy of measuring robot and monitoring data. The method has practical significance in slope monitoring and accurate warning.

TABLE V.

STATIONS 1 AND 2 WITH DIFFERENT CYCLE ORIENTATION ANGLE DEVIATIONS (IN ")

\begin{tabular}{|c|c|c|c|c|c|}
\hline $\begin{array}{l}\text { Station } \\
\text { Cycle }\end{array}$ & $\begin{array}{c}1 \\
(")\end{array}$ & $\begin{array}{c}2 \\
(")\end{array}$ & $\begin{array}{c}3 \\
(")\end{array}$ & $\begin{array}{c}4 \\
(")\end{array}$ & $\begin{array}{c}5 \\
(")\end{array}$ \\
\hline No. 1 & 3.75 & -4.77 & 4.14 & -5.59 & 4.36 \\
\hline No. 2 & -5.06 & 4.38 & 3.95 & -3.01 & 3.46 \\
\hline
\end{tabular}

TABLE VI.

CORRECTION VALUES (/M) FOR FIVE MONITORING POINTS IN X,Y DIRECTION IN STATION 1

\begin{tabular}{cccccc}
\hline Point No. & $\mathbf{6 1}$ & $\mathbf{1 0}$ & $\mathbf{1 1}$ & $\mathbf{1 2}$ & $\mathbf{2}$ \\
\hline Side length & 709.973 & 846.601 & 966.138 & 994.418 & 1069.152 \\
Measured Azimuth & $357^{\circ} 41^{\prime} 15.81^{\prime \prime}$ & $321^{\circ} 59^{\prime} 58.31^{\prime \prime}$ & $313^{\circ} 20^{\prime} 10.82^{\prime \prime}$ & $308^{\circ} 56^{\prime} 48.20^{\prime \prime}$ & $308^{\circ} 10^{\prime} 45.13^{\prime \prime}$ \\
$\Delta \alpha$ & $-4.32^{\prime \prime}$ & $-4.32^{\prime \prime}$ & $-4.32^{\prime \prime}$ & $-4.32^{\prime \prime}$ & $-4.32^{\prime \prime}$ \\
$\Delta x$ & 0.025 & -0.004 & -0.011 & -0.012 & -0.009 \\
$\Delta y$ & -0.016 & -0.019 & -0.018 & -0.018 & -0.025 \\
\hline
\end{tabular}

TABLE VII.

TEN CYCLES IN THE NO. 3 SPOT IN X AND Y DIRECTIONS BEFORE AND AFTER CORRECTION (/M)

\begin{tabular}{|c|c|c|c|c|c|c|c|c|c|c|}
\hline Cycles & 1 & 2 & 3 & 4 & 5 & 6 & 7 & 8 & 9 & 10 \\
\hline $\mathrm{X}$ direction before correction & 0.0000 & 0.0234 & 0.0256 & 0.0136 & 0.0186 & 0.0114 & -0.0038 & 0.0222 & 0.021 & 0.0124 \\
\hline $\mathrm{X}$ direction after correction & 0.0000 & 0.0045 & 0.0065 & 0.0071 & 0.0075 & 0.0093 & 0.0150 & 0.0116 & 0.0128 & 0.0141 \\
\hline Y direction before correction & 0.0000 & 0.0278 & 0.0090 & 0.0104 & 0.0226 & 0.0298 & 0.0184 & 0.0340 & 0.0120 & 0.0242 \\
\hline Y direction after correction & 0.0000 & 0.0049 & 0.0063 & 0.0067 & 0.0069 & 0.0082 & 0.0120 & 0.0097 & 0.0105 & 0.0114 \\
\hline
\end{tabular}

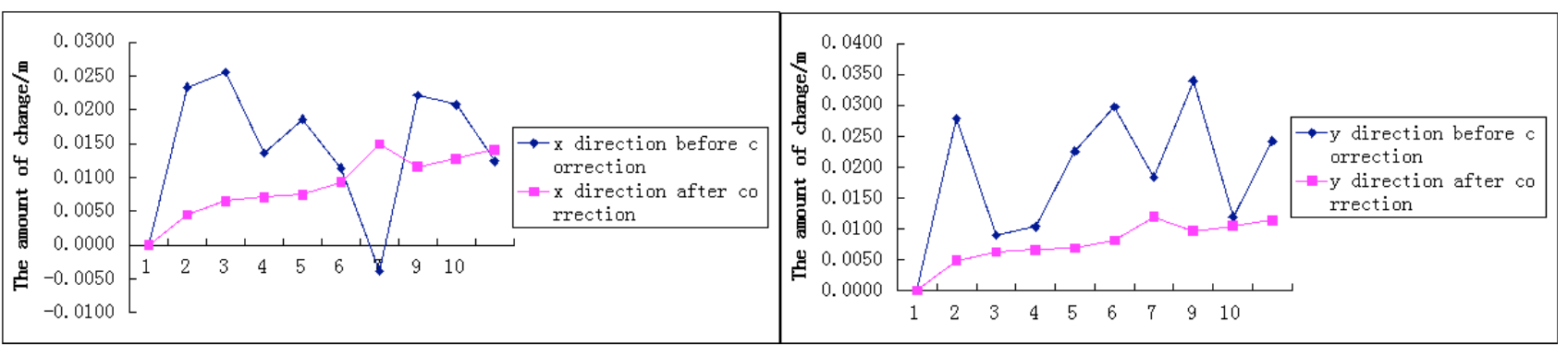

Figure 8. Comparison of the 10 cycles in No. 3 spot in $\mathrm{x}$ and $\mathrm{y}$ directions before and after the correction of deformation monitoring curves 


\section{CONCLUSIONS}

Open-air monitoring data with 10 cycles from Dagushan iron mine were utilized as data sources to analyze the main factors that affect the accuracy of measuring robot. A measurement robot was utilized to collect data, and an effective method to improve the accuracy of measuring robot was developed. The effectiveness of the method was verified, and the method achieved good results. The main results are as follows.

1. The physical quantities of atmospheric refraction (air pressure, temperature, and relative humidity) affect the measuring robot. The base side length data accuracy measurements indicate that the impact on the accuracy of the physical side length increases with atmospheric refraction; the side length also increases when the temperature is at significant values. Accurately obtaining the average temperature range of the optical path of the curve to correct the side length is an effective method to improve the accuracy of the slope distance.

2. Directional bias is another major factor in the quality of measuring robot. Monitoring the impact of accuracy in a multi-cycle monitoring process demonstrated uncertainty in size and direction. However, for the same period, each point group showed a consistent size and direction. The actual monitoring data processing results show that directional bias correction is an effective means to improve the accuracy of measuring robot.

3. The method described above was applied to actual monitoring data. The monitoring points in the multicycle process showed consistency in displacement and have the same direction with the monitoring points where displacement may occur. This result proves that the proposed method is effective for improving the accuracy of measuring robot.

\section{REFERENCES}

[1] Zhu L, "Measurement precision and accuracy."Moderd science, no.4, pp.258, February 2009.

[2] Peng M, Li X Y, Li D Q, Jiang S H, Zhang L M, "Slop safety evaluation by integrating multi-source monitoring information." Structural Safety, vol.49(S1), pp. 65-74, July 2014. http://dx.doi.org/10.1016/j.strusafe.2013.08.007

[3] Xu N W, Tang C A, Li L C, Zhou Z, Sha C, Liang Z Z, Yang J Y, "Microseismic monitoring and stability analysis of the left bank in Jinping first stage hydropower station in southwestern China." International Journal of Rock Mechanics and Mining Sciences, vol.48, no.6, pp. 950-963, September 2011. http://dx.doi.org/10.1016/j.ijrmms.2011.06.009

[4] Han X, He M C, Zhang B, "Sensitivity analysis for parameters of a monitoring system for steep slopes of open-pit mines." Mining Science and Technology, vol.19, no.4, pp. 441-445, October 2009.

[5] Wang J P, Gao J X, Liu C, and Wang J, "High precision slope deformation monitoring model based on the GPS/Pseudolites technology in open-pit mine." Mining Science and Technology, vol.20, no.1 , pp. 126-132, January 2010.

[6] Gruber V, Marcelino R, Silva J B, "Technology PLC-Power line communication used in monitoring systems online.".International Journal of Online Engineering, vol.9(S1), pp.22-25, January 2013.

[7] Jiang C G, Pang X Z, Dong Q J, et al, "Development and application of the automatic slope monitoring system in open-pit mine." Beijing Surveying and Mapping, vol.17, no.4, pp. 123-128, 2006.
[8] Mei W S, Zhang Z L, Huang Q Y, "Application of robotic total station in deformation monitoring." Dam and Safety, vol.27, no.5, pp.123-128,July 2002.

[9] Mei W S, Zhang Z L, Guo B M, et al, "Study on system of deformation monitoring system with robotic total station.".Journal of Wuhan University, vol.27, no.2, pp.165-171, April 2002.

[10] Mao Y C, Wang E D, Chen Y S, Yang Y Z, "Problems and Solutions to Developing Automatic Deformation Monitoring Software for Surveying Robot with GEOCOM “"Metal Mine, vol.39, no.3, pp.94-96, March 2010.

[11] Ma Z L, Ji C D, and Ren D F, "Application of GPS and the surveying robot joint operation mode in open-pit mine deformation monitoring." Mine Surveying, no.1, pp.41-43, April 2007.

[12] Liu D A, Yang Z F, Tang C H, Wang J and Liu Y, "An automatic monitoring system for the shiplock slop of Wuqiangxi Hydropower Station."Engineering Geology, vol.76 no(1-2), pp. 79-91, June 2004.

[13] Zhao Y Q,“A New Type of Automatic Monitoring System of Static and Dynamic Displacement on Dam and Slop." Procedia Engineering. no.43, pp. 387-392, 2012.

[14] Dong Q W,"Influence of meteorological conditions on the accuracy of total station instrument ranging." Gansu science and technology, vol.28, no.12, pp.204, October 2012 .

[15] Li J P,"Variation of meteorological factors and the instrument constant and the influence on wire ranging precision."Urban exploration and survey, no.3, pp.22, September 2000.

[16] Yao H, Chen S Y,"Total Station's Meteorological Correction Formula and the Influence of Measuring Precision of Meteorological Element on Distance."Bulletin of Surveying and mapping, vol.0, no.4, pp.413, July 2008.

[17] Leica Geosystems Ltd. Leica TS30/TM30 User's manual.

[18] Cheng G R, Zhao Y, Li P C,"Deformation Monitoring of Dam External Based on TM30 and Data Processing."Geomatics \& Spatial Information Technology, vol .18, no.3, April 2014.

[19] Zhu S P, Xue Y, "Rationale, calibration \& Testing of ATR."Beijing Surveying and mapping, no.3, pp.204, December 2005.

[20] Lin F C, Liu X,"Position measurement method based on linear array CCD with inverting prism."Journal of Zhejiang University, vol.40, no.6, pp.274, july 2006.

[21] Guo T L, Yue J P, Liu Y.”Researching for Measurement Robot's ATR Intelligent Measurement Program."Modern Surveying and mapping, vol.34, no.2 pp.209, September 2011.

[22] Guo T L, Yue J P, "The Analysis and Test of GeoRobot ATR Performance." Bulletin of Surveying and mapping ,vol.0, no.8, pp.209, October 2012.

[23] Mao Y C, Chen Y S, Wang S H, Betoubert Roaj "Model of Gross Error Elimination for Monitoring Data Collected by A Surveying Robot."Journal of Engineering Science and Technology Review, vol.7, no.4, pp.13-17, September 2014.

\section{AUTHORS}

Yandong GAO is with the College of Mining Engineering Institute,University of Science and Technology Liaoning, Anshan, 114051, China (747804303@qq.com).

Maolin XU is with the College of Science and Technology,University of Science and Technology Liaoning,Anshan,114051 China (xm11964@163.com).

Yachun Mao is a professor in Institute for Geoinformatics \& Digital Mine Research, Northeastern University, China. His research interests include theories and key technologies of digital mining, $3 \mathrm{~d}$ geological modeling, and the technology of $3 \mathrm{~S}$ integration, mine surveying and mapping technology (dbdxmyc@163.com).

The authors are grateful for the support provided by the National Natural Science Foundation of China (No. 41371437). Submitted 20 November 2014. Published as resubmitted by the authors 25 January 2015. 